\title{
Which urinary drainage method is better tolerated in patients with hydronephrosis secondary to ureteral obstruction following onco-gynecology surgeries? A comparison of health-related quality of life
}

\author{
Ismail Selvi* \\ Department of Urology, Karabuk University Training and Research Hospital, Karabuk, Turkey
}

\begin{abstract}
Objective: We aimed to compare the impacts of retrograde ureteral stent (RUS) and percutaneous nephrostomy (PCN) which were placed for hydronephrosis secondary to onco-gynecology surgeries on health-related quality of life.

Materials and methods: The datas of 42 patients who required placement of RUS or PCN for hydronephrosis secondary to onco-gynecology surgeries and followed up between January 2013 and December 2017 were retrospectively evaluated. Patients were divided into two groups: RUS (n:19) and PCN (n:23). We compared the health-related quality of life and catheter related undesirable symptoms between two groups.

Results: In the evaluation of patients' physical and psychosocial well-being, problems related to mobility $(\mathrm{p}=0.002)$, self care $(\mathrm{p}=0.01)$, daily physical activity ( $\mathrm{p}=0.01$ ) and severity of anxiety/depression ( $\mathrm{p}<0.001)$ were found higher in PCN group. On the other hand, pain ( $\mathrm{p}=0.001)$ and daily need of analgesia $(\mathrm{p}=0.016)$ were higher in patients with RUS. Dysuria $(\mathrm{p}=0.038)$, urgency $(\mathrm{p}=0.038)$ and frequency $(\mathrm{p}=0.006)$ were catheter related undesired symptoms and they were significantly higher in RUS group. We used VAS score as an indicator of general well-being. VAS scores were $5.42 \pm 1.53$ and $4.70 \pm 1.29$ in RUS and PCN groups, respectively $(p=0.105)$.

Conclusion: RUS and PCN have equally success for urgent decompression of upper urinary tract. In the patients with hydronephrosis secondary to ureteral obstruction following onco-gynecology surgeries, we observed that none of two urinary drainage methods was better tolerated in terms of general well-being. However, physical and psychosocial well-being was worse in PCN group.
\end{abstract}

\section{Introduction}

Gynecologic cancers has a high incidence. Among them, cervical and endometrial cancers are the third and fifth most common cancer in the world, respectively [1]. The current multimodal treatment approach in the cases of onco-gynecology include combinations of surgery, chemotherapy and radiotherapy [2]. Although radical surgery is the first line process, it require attention to preserve other non-gynecological neighboring structures during excision of the gynecological tumors [3]. In the course of major onco-gynecology surgeries, urethra, bladder and ureters are at potential risk of accidental operative injuries because of their close anatomical proximity of the female genital tract. In addition, partial or total resection of urological structures may be necessary to provide complete tumor eradication in some cases. As a result, development of hydronephrosis, ureteral obstruction or genitourinary fistula may be seen as complications following these procedures [4].

When urinary drainage is blocked by ureteral obstruction associated with onco-gynecology surgery, urinary diversion is essential for restoring renal functions [5]. The drainage is provided by percutaneous nephrostomy (PCN) or retrograde ureteral stent (RUS). Even though each procedure have similar efficacy and complication rates to decompress the obstructed urinary system, quality of life may vary between procedures [6].

We evaluated the patients who required placement of PCN and RUS for hydronephrosis secondary to onco-gynecology surgeries.
Our aim is to investigate impact of each urinary diversion technique on health-related quality of life (HRQoL).

\section{Materials and methods}

The datas of 42 patients who required placement of PCN or RUS for hydronephrosis secondary to onco-gynecology surgeries and followed up at Department of Urology, Ankara Oncology Training and Research Hospital between January 2013 and December 2017 were retrospectively evaluated. The study was conducted in compliance with the Declaration of Helsinki.

Hydronephrosis was defined as a result of ureteral obstruction or iatrogenic injury related to previous onco-gynecology surgeries. The computerized tomography or ultrasound, presence of flank pain, increased serum creatinine and estimated glomerular filtration rate (eGFR) were used for confirmation of hydronephrosis. eGFR

${ }^{*}$ Correspondence to: Ismail SELVI, MD, FEBU, Department of Urology, Karabuk University Training and Research Hospital, 78200, Karabuk, Turkey, Tel: +90 037041580 00; Fax: +90 037041256 28; E-mail: ismselvi33@hotmail.com

Key words: health-related quality of life, hydronephrosis, onco-gynecology surgeries, percutaneous nephrostomy, retrograde ureteral stent

Received: February 11, 2019; Accepted: March 08, 2019; Published: March 12 , 2019 
Selvi I (2019) Which urinary drainage method is better tolerated in patients with hydronephrosis secondary to ureteral obstruction following onco-gynecology surgeries? A comparison of health-related quality of life

was calculated by short-term Modification of Diet of Renal Disease (MDRD) formula. Preoperative creatinine, age, gender and race were used for this formula.

Demographic and clinical characteristics of the patients, type of malignancy, laboratory datas at the time of catheter insertion were recorded from the patient files. All patients included in the study were selected among those who were followed for at least 6 months and whose catheters were replaced every three months. The patients with complete data were divided into two groups: RUS (n:19) and PCN (n:23). We evaluated the presence of lower urinary tract symptoms such as hematuria, dysuria, urgency, frequency. The development of urinary system infection, daily need of analgesia and need of help in daily care were also recorded according to patients anamnesis. The bag leak/slippage was recorded for PCN group, whereas ureteral stent migration/dislocation was recorded for RUS group. As a part of our patient follow-up approach, at least six months after the catheter insertion, the mini-questionnaire was used for assessing the impact of each urinary diversion techniques on HRQoL.

\section{Intervention techniques of retrograde ureteral stent and percutaneous nephrostomy}

The placement of RUS was performed under spinal anesthesia. After providing sterile urine before the procedure and administering prophylactic antibiotic (one gram of cefazolin intravenously), a 17 Fr endoscope (Karl Storz, Germany) was introduced into the urethral meatus in lithotomy position. After visualizing the bladder uroepithelium and the ureteral orifices, a sensor PTFE-Nitinol Guidewire (Boston Scientific) was passed through the ureteral orifice. A 6 Fr open-ended double J stent $(26 \mathrm{~cm}, 0.035$ ", silicone based, Elit Medikal) was placed in the collecting system by sliding over the sensor guidewire.

For PCN implementation, the intervention planned access tract and the calyx were determined with ultrasonography on prone position. For local anesthesia, five milligrams of lidocaine was injected into the acsess tract through skin. The access into the planned calyx was performed via a nephrostomy needle with the guidance of ultrasound. A guide-wire was passed from the needle into the collecting system.
After dilation of the tract with serial dilators, a 8 Fr nephrostomy tube (Boston Scientific) was implanted. The tube was fixed to the skin with $2 / 0$ silk sutures following the urine output.

\section{Design of mini-questionnaire for evaluating HRQoL}

Our mini-questionnaire consists of two parts. The first part contains five questions related to physical and psychosocial well-being. The questions are related to those problems: Mobility, self-care, daily physical activities, pain and anxiety/depression. Each five questions have three levels of answer (never, sometimes, usually). Each question is graded from 1 point to 3 points. Sum of the points forms the total score. The second part is Visual Analogue Scale (VAS). The scale is graded from 0 points (the best health state) to 10 points (the worst health state) by the patients. VAS score is used for evaluation of general well-being which also contains catheter related undesirable lower urinary tract symptoms besides physical and psychosocial well-being.

\section{Statistical analysis}

Kolmogorov-Smirnov and Shapiro-Wilk tests were used for evaluating normality status. Independent sample $t$ test or Mann Whitney $U$ test for continuous variables and Pearson Chi-square or Fisher's Exact analysis for categorical variables were used. The analyzes were performed by using IBM SPSS Statistics 21 (IBM, Armonk, NY USA) software. $\mathrm{p}<0.05$ was considered statistically significant.

\section{Results}

The mean age of the 42 female patients included in our study was $60.07 \pm 7.81$. Among these patients, 18 (42.9\%) had ovarian cancer $20(47.6 \%)$ had cervical cancer, 4 (9.5\%) had endometrial cancer. All these patients had catheters (RUS or PCN) because of postoperative hydronephrosis secondary to ureteral obstruction. They were followed for at least 6 months with their catheters and the catheters were replaced every three months. At the time of evaluation of the quality of life, 14 (33.4\%) patients were in the localized stage, 28 (66.6\%) patients were in the metastatic stage. The patients' demographic, clinical data, presence of undesirable symptoms related to catheters and evaluation of healthrelated quality of life are shown in Table 1.

Table 1. The patients' demographic, clinical data and evaluation of health-related quality of life

\begin{tabular}{|c|c|c|c|c|}
\hline Parameters & $\begin{array}{c}\text { Group I } \\
\text { RUS } \\
\text { (n: } 19, \mathbf{4 5 . 2 \% )}\end{array}$ & $\begin{array}{c}\text { Group II } \\
\text { PCN } \\
\text { (n: } 23,54.8 \%)\end{array}$ & $\begin{array}{c}\text { Total } \\
\text { (n: } 42, \mathbf{1 0 0} \%)\end{array}$ & p value \\
\hline $\begin{array}{l}\text { Age (years) } \\
\text { (mean } \pm \text { standard deviation) }\end{array}$ & $57.84 \pm 8.80$ & $61.69 \pm 6.50$ & $60.07 \pm 7.81$ & $\dagger 0.093$ \\
\hline $\begin{array}{l}\text { Body mass index }\left(\mathrm{kg} / \mathrm{m}^{2}\right) \\
(\text { mean } \pm \text { standard deviation })\end{array}$ & $25.37 \pm 2.50$ & $24.84 \pm 2.60$ & $25.08 \pm 2.54$ & $\dagger 0.503$ \\
\hline $\begin{array}{l}\text { Creatinine } \\
\text { (median, 25th-75th percentile) }\end{array}$ & $2.99(2.37-3.90)$ & $3.05(2.81-3.25)$ & $3.03(2.78-3.34)$ & $\S 0.84$ \\
\hline $\begin{array}{l}\text { Estimated glomerular filtration rate (eGFR) } \\
\text { (median, 25th-75th percentile) }\end{array}$ & $\begin{array}{c}61.62 \\
(59.43-68.31)\end{array}$ & $\begin{array}{c}62.55 \\
(58.07-64.59)\end{array}$ & $\begin{array}{c}62.08 \\
(58.39-66.46)\end{array}$ & $\S 0.695$ \\
\hline $\begin{array}{l}\text { Degree of hydronephrosis }(\mathrm{n}, \%) \\
\text {-II } \\
\text {-III }\end{array}$ & $\begin{array}{l}11(57.9) \\
8(42.1)\end{array}$ & $\begin{array}{l}13(56.5) \\
10(43.5)\end{array}$ & $\begin{array}{l}24(57.1) \\
18(42.9)\end{array}$ & $\$ 0.929$ \\
\hline $\begin{array}{l}\text { Hypertension }(\mathrm{n}, \%) \\
\text {-Present } \\
\text {-Absent }\end{array}$ & $\begin{array}{c}7(36.8) \\
12(63.2)\end{array}$ & $\begin{array}{c}8(34.8) \\
15(65.2)\end{array}$ & $\begin{array}{l}15(35.7) \\
27(64.3)\end{array}$ & $\$ 0.89$ \\
\hline $\begin{array}{l}\text { Diabetes mellitus (n, \%) } \\
\text {-Present } \\
\text {-Absent }\end{array}$ & $\begin{array}{c}6(31.6) \\
13(68.4)\end{array}$ & $\begin{array}{l}11(47.8) \\
12(52.2)\end{array}$ & $\begin{array}{l}17(40.5) \\
25(59.5)\end{array}$ & $\$ 0.286$ \\
\hline $\begin{array}{l}\text { Smoking (n, \%) } \\
\text {-Present } \\
\text {-Absent }\end{array}$ & $\begin{array}{l}11(57.9) \\
8(42.1)\end{array}$ & $\begin{array}{l}11(47.8) \\
12(52.2)\end{array}$ & $\begin{array}{l}22(52.4) \\
20(47.6)\end{array}$ & $\$ 0.516$ \\
\hline
\end{tabular}


Selvi I (2019) Which urinary drainage method is better tolerated in patients with hydronephrosis secondary to ureteral obstruction following onco-gynecology surgeries? A comparison of health-related quality of life

\begin{tabular}{|c|c|c|c|c|}
\hline $\begin{array}{l}\text { Tumor type }(\mathrm{n}, \%) \\
\text {-Ovarian } \\
\text { - Cervical } \\
\text { - Endometrial }\end{array}$ & $\begin{array}{c}7(36.8) \\
10(52.6) \\
2(10.5)\end{array}$ & $\begin{array}{c}11(47.8) \\
10(43.5) \\
2(8.7)\end{array}$ & $\begin{aligned} 18 & (42.9) \\
20 & (47.6) \\
4 & (9.5)\end{aligned}$ & $\$ 0.774$ \\
\hline $\begin{array}{l}\text { Problems related to mobility }(\mathrm{n}, \%) \\
\text {-Never } \\
\text {-Sometimes } \\
\text {-Usually }\end{array}$ & $\begin{array}{l}9(47.4) \\
8(42.1) \\
2(10.5)\end{array}$ & $\begin{array}{c}1(4.3) \\
11(47.8) \\
11(47.8)\end{array}$ & $\begin{array}{l}10(23.8) \\
19(45.2) \\
13(31.0)\end{array}$ & $\$ 0.002 *$ \\
\hline $\begin{array}{l}\text { Problems related to self care }(\mathrm{n}, \%) \\
\text {-Never } \\
\text {-Sometimes } \\
\text {-Usually }\end{array}$ & $\begin{array}{c}9(47.4) \\
9(47.4) \\
1(5.3)\end{array}$ & $\begin{array}{c}3(13.0) \\
11(47.8) \\
9(39.1)\end{array}$ & $\begin{array}{l}12(28.6) \\
20(47.6) \\
10(23.8)\end{array}$ & $\$ 0.01 *$ \\
\hline $\begin{array}{l}\text { Problems related to daily } \\
\text { physical activity (n, \%) } \\
\text {-Never } \\
\text {-Sometimes } \\
\text {-Usually }\end{array}$ & $\begin{array}{c}8(42.1) \\
11(52.6) \\
1(5.3)\end{array}$ & $\begin{array}{c}2(8.7) \\
13(56.5) \\
8(34.8)\end{array}$ & $\begin{array}{c}10(23.8) \\
23(54.8) \\
9(21.4)\end{array}$ & $\$ 0.01 *$ \\
\hline $\begin{array}{l}\text { Severity of pain }(\mathrm{n}, \%) \\
\text {-Never } \\
\text {-Sometimes } \\
\text {-Usually }\end{array}$ & $\begin{array}{l}3(15.8) \\
9(47.4) \\
7(36.8)\end{array}$ & $\begin{array}{l}14(60.9) \\
9(39.1) \\
0(0.0)\end{array}$ & $\begin{array}{c}17(40.5) \\
18(42.9) \\
7(16.7)\end{array}$ & $\$ 0.001 *$ \\
\hline $\begin{array}{l}\text { Severity of anxiety / depression (n, \%) } \\
\text {-Never } \\
\text {-Sometimes } \\
\text {-Usually }\end{array}$ & $\begin{array}{c}11(57.9) \\
7(36.8) \\
1(5.3)\end{array}$ & $\begin{array}{c}1(4.3) \\
12(52.2) \\
10(43.5)\end{array}$ & $\begin{array}{l}12(28.6) \\
19(45.2) \\
11(26.2)\end{array}$ & $\$<0.001^{*}$ \\
\hline $\begin{array}{l}\text { Points of mini-questionnaire } \\
\text { related to HRQoL } \\
\text { (mean } \pm \text { standard deviation) }\end{array}$ & $8.53 \pm 1.67$ & $10.74 \pm 1.17$ & $9.74 \pm 1.79$ & $\dagger<0.001^{*}$ \\
\hline $\begin{array}{l}\text { VAS score } \\
\text { (mean } \pm \text { standard deviation) }\end{array}$ & $5.42 \pm 1.53$ & $4.70 \pm 1.29$ & $5.02 \pm 1.44$ & $\dagger 0.105$ \\
\hline $\begin{array}{l}\text { Hematuria }(n, \%) \\
\text {-Present } \\
\text {-Absent }\end{array}$ & $\begin{array}{c}8(42.1) \\
11(57.9)\end{array}$ & $\begin{array}{c}8(34.8) \\
15(65.2)\end{array}$ & $\begin{array}{l}16(38.1) \\
26(61.9)\end{array}$ & $\$ 0.627$ \\
\hline $\begin{array}{l}\text { Dysuria }(n, \%) \\
\text {-Present } \\
\text {-Absent }\end{array}$ & $\begin{array}{l}10(52.6) \\
9(47.4)\end{array}$ & $\begin{array}{c}5(21.7) \\
18(78.3)\end{array}$ & $\begin{array}{l}15(35.7) \\
27(64.3)\end{array}$ & $\$ 0.038^{*}$ \\
\hline $\begin{array}{l}\text { Urgency }(\mathrm{n}, \%) \\
\text {-Present } \\
\text {-Absent }\end{array}$ & $\begin{array}{c}10(52.6) \\
9(47.4)\end{array}$ & $\begin{array}{c}5(21.7) \\
18(78.3)\end{array}$ & $\begin{array}{l}15(35.7) \\
27(64.3)\end{array}$ & $\$ 0.038^{*}$ \\
\hline $\begin{array}{l}\text { Frequency (n, \%) } \\
\text {-Present } \\
\text {-Absent }\end{array}$ & $\begin{array}{c}12(63.2) \\
7(36.8)\end{array}$ & $\begin{array}{c}5(21.7) \\
18(78.3)\end{array}$ & $\begin{array}{l}17(40.5) \\
25(59.5)\end{array}$ & $\$ 0.006^{*}$ \\
\hline $\begin{array}{l}\text { Urinary tract infection }(\mathrm{n}, \%) \\
\text {-Present } \\
\text {-Absent }\end{array}$ & $\begin{array}{c}5(26.3) \\
14(73.7)\end{array}$ & $\begin{array}{c}6(26.1) \\
17(73.9)\end{array}$ & $\begin{array}{l}11(26.2) \\
31(73.8)\end{array}$ & ๆ 0.629 \\
\hline $\begin{array}{l}\text { Daily need of analgesia }(\mathrm{n}, \%) \\
\text {-Present } \\
\text {-Absent }\end{array}$ & $\begin{array}{c}11(57.9) \\
8(42.1)\end{array}$ & $\begin{array}{c}5(21.7) \\
18(78.3)\end{array}$ & $\begin{array}{l}16(38.1) \\
26(61.9)\end{array}$ & $\$ 0.016^{*}$ \\
\hline $\begin{array}{l}\text { Need of help in daily care }(n, \%) \\
\text {-Present } \\
\text {-Absent }\end{array}$ & $\begin{array}{c}2(10.5) \\
17(89.5)\end{array}$ & $\begin{array}{c}5(21.7) \\
18(78.3)\end{array}$ & $\begin{array}{c}7(16.7) \\
35(83.3)\end{array}$ & ๆ 0.428 \\
\hline $\begin{array}{l}\text { Ureteral stent migration/dislocation or } \\
\text { the PCN bag leak/slippage (n, \%) } \\
\text {-Present } \\
\text {-Absent }\end{array}$ & $\begin{array}{l}4(21.1) \\
15(78.9)\end{array}$ & $\begin{array}{c}8(34.8) \\
15(65.2)\end{array}$ & $\begin{array}{l}12(28.6) \\
30(71.4)\end{array}$ & $\$ 0.327$ \\
\hline
\end{tabular}

$*^{*} \mathrm{p}<0.05$ Asteriks $(*)$ indicates statistical significance. RUS: Retrograde ureteral stent, PCN: Percutaneous nephrostomy, HRQoL: health-related quality of life, VAS: Visual Analogue Scale, $\dagger$ Independent sample t test,, Chi-square, $\S$ Mann-Whitney $U$, $\uparrow$ Fisher's exact test

Age, body mass index, creatinine, eGFR, degree of hydronephrosis, rates of hypertension, diabetes mellitus and smoking were not significantly different between two groups (Table 1). The similarity of creatinine, eGFR, and degree of hydronephrosis shows that the effects of both techniques on renal functions are equal. In the evaluation of patients' physical and psychosocial well-being, problems related to mobility ( $p=0.002)$, self care $(p=0.01)$, daily physical activity $(p=0.01)$ and severity of anxiety/depression $(\mathrm{p}<0.001)$ were found higher in PCN group. Severity of pain related to catheter was another parameter of this evaluation and pain was higher in patients with RUS ( $\mathrm{p}=0.001)$. Daily need of analgesia was higher in RUS group associated with this result $(\mathrm{p}=0.016)$. The total points of these five parameters form physical and psychosocial well-being. The sum of these points were lower in RUS group $(8.53 \pm 1.67$ vs. $10.74 \pm 1.17, \mathrm{p}<0.001)$ and the lower scores indicated better HRQoL.

We did not state a difference in terms of hematuria $(p=0.627)$, urinary tract infection $(\mathrm{p}=0.629)$, need of help in daily care $(\mathrm{p}=0.428)$, ureteral stent migration/dislocation or the PCN bag leak/slippage $(\mathrm{p}=0.327)$. Dysuria $(\mathrm{p}=0.038)$, urgency $(\mathrm{p}=0.038)$ and frequency $(\mathrm{p}=0.006)$ were observed as lower urinary tract symptoms related to catheter and all three symptoms were significantly higher in RUS group. VAS score is an indicator of general well-being and it signifies both physical, psychosocial well-being and catheter related undesirable lower urinary tract symptoms. VAS scores were $5.42 \pm 1.53$ and $4.70 \pm$ 
Selvi I (2019) Which urinary drainage method is better tolerated in patients with hydronephrosis secondary to ureteral obstruction following onco-gynecology surgeries? A comparison of health-related quality of life

1.29 in RUS and PCN groups, respectively $(\mathrm{p}=0.105)$. No differences were found between each techniques in terms of general well-being.

\section{Discussion}

Ureteral obstructions related to onco-gynecology surgeries can cause very serious complications such as obstructive pyelonephritis and acute renal failure. Therefore, drainage of upper urinary tract obstruction via PCN or RUS is mandatory. The superiority of these two techniques to each other has not been shown yet. They are accepted to have equal efficacy [7]. To our knowledge, this is the first study to compare the effects of each urinary diversion techniques on healthrelated quality of life in patients undergoing onco-gynecology surgery. The previous studies comparing two techniques have evaluated patients with hydronephrosis secondary to ureteral stones or pregnancy [7-9]. Most of these studies have investigated the effect of two methods on the improvement of ureteral obstruction and renal function. There are few publications evaluating the effects of two techniques on patients' quality of life.

According to Makhmali et al. [10] and Goldsmith et al. [11], both techniques were effective in case of ureteral stones with obstructive uropathy and sepsis. However, $\mathrm{PCN}$ was generally preferred in patients with more severely illness. In this context, it is more important to investigate which procedure affects patients' quality of life better. Morais et al. [7] evaluated HRQoL with VAS score and the questionnaire of "EuroQol EQ-5D-3L". This questionnaire was developed for the measurement of health status by international multidisciplinary researchers (The EuroQol Group). They repeated HRQoL assessment 30-40 days after the initial urinary diversion. They observed a significant decrease in VAS score in RUS group, whereas no significant alteration on quality of life was observed in PCN group. In our study, VAS score was used for measurement of general well-being and there was no a significant difference between groups according to our results.

Morais et al. [7] stated that the patients reported more problems related to quality of life following the placement of ureteral stent in evaluation of EuroQol EQ-5D-3L. In a similar study, there was seen an increase only in terms of anxiety/depression in PCN group. The researchers thought that it might be based on the presence of the extracorporeal catheter [12]. PCN tube was not found aesthetic by the patients because of body image disfiguration [7]. But according to overall quality of life assessment, their results were consistent with the findings of Mokhmalji et al. [10]. Each studies observed an increase of about $7 \%$ in quality of life index following the placement of PCN $[10,12]$. In our study, anxiety/depression was higher in PCN group as similar to mentioned above studies. However, while the quality of life index increased in these studies, worsening in physical and psychosocial well-being was observed in our PCN group.

In the previous studies, the existing catheter-related symptoms have been investigated in case of hydronephrosis secondary to ureter stones $[7,13,14]$. Hematuria, dysuria and urgency are the most common lower urinary tract symptoms in patients with ureteral stent $[6,13]$. It was also documented that patients with ureteral stents were more prone to have pain as compared to patients with PCN and they needed more analgesics for relief of pain $[7,10]$. We did not observe a difference in terms of hematuria but dysuria, urgency and pain were higher in patients with RUS. On the other hand, one of the most serious problems in terms of quality of life in patients with PCN was the troubles related to collection bag [7]. A better patient information about care of PCN catheter and collecting bag is necessary to avoid frequent hospital visits. However, PCN bag leak was not reported as main problem according to our results. According to the literature, the cost associated with RUS was found more than twice of PCN. In addition, need for medication due to pain and lower urinary tract symptoms following RUS increased cost. Therefore, RUS has not been seen cost-effective $[12,15]$. But we did not evaluate cost analysis in our study.

Although RUS and PCN are recommended as equally effective for urgent decompression of upper urinary tract, the dislocation of RUS can be seen frequently in pregnant women due to the influence of hormonal and mechanical factors on ureter [8]. But the rates of ureteral stent migration/dislocation or PCN bag leak/slippage was not significantly differ between two techniques according to our results. Severe disturbing symptoms such as dysuria, urgency, flank or suprapubic pain may occur in female patients who have been implanted RUS due to hydronephrosis of pregnancy [8]. Approximately 16-32\% of the stents had to be removed before the scheduled time due to these undesirable effects $[16,17]$. Because there is no extra general anesthesia requirement, the application of PCN by local anesthesia may protect the pregnant women and their fetuses from the potential side effects of general anesthesia [18]. PCN require less re-intervention and the reintervention time is longer as compared with RUS. As a result, PCN is more effective and feasible in especially pregnant women [8]. In our patients underwent onco-gynecology surgeries, none of two urinary drainage method was better tolerated in terms of general well-being. In addition, physical and psychosocial well-being was worse in our PCN group.

Our main limitations were retrospective, non randomized design with low patient population in a single center. Furthermore, external validated international surveys such as The European Organization of Research and Treatment of Cancer Quality of Life Questionnaire or the 36-Item Short Form Health Survey (SF 36) were not used in our assessment. Prospective, randomized, controlled, multicenter, longterm follow-up studies which use external validated international surveys with larger numbers of patients are needed to support our results.

\section{Conclusion}

Although it has been reported that RUS causes less anxiety/ depression and less worsening in physical and psychosocial wellbeing, the severity of pain and lower urinary tract symptoms are more common in this technique. Therefore, it is not easy to determine that one technique is better tolerated than the other in terms of general wellbeing.

\section{Conflict of interest}

None.

\section{References}

1. Ferlay J, Soerjomataram I, Dikshit R, Eser S, Mathers C, et al. (2014) GLOBOCAN 2012 v1.0, Cancer Incidence and Mortality Worldwide: IARC CancerBase No. 11, International Agency for Research on Cancer.

2. Costantini B, Vizzielli G, Fanfani F, D'Addessi A, Ercoli A, et al. (2014) Urologic surgery in gynecologic oncology: a large single-institution experience. Eur J Surg Oncol 40: 756-761. [Crossref]

3. Kehoe S (2006) Treatments for gynecological cancers. Best Pract Res Clin Obstet Gynaecol 20: 985-1000.

4. Minár L, Weinberger V, Kysela $\mathrm{P}$ (2010) Complications of radical oncogynecological operations. Ceska Gynekol 75: 346-352. [Crossref]

5. Yoon JH, Park S, Park S, Moon KH, Cheon SH, et al. (2018) Renal function is associated with prognosis in stent-change therapy for malignant ureteral obstruction. Investig Clin Urol 59: 376-382. [Crossref] 
Selvi I (2019) Which urinary drainage method is better tolerated in patients with hydronephrosis secondary to ureteral obstruction following onco-gynecology surgeries? A comparison of health-related quality of life

6. Joshi HB, Adams S, Obadeyi OO, Rao PN (2001) Nephrostomy tube or 'JJ' ureteric stent in ureteric obstruction: assessment of patient perspectives using quality-of-life survey and utility analysis. Eur Urol 39: 695-701. [Crossref]

7. de Sousa Morais N, Pereira JP, Mota P, Carvalho-Dias E, Torres JN, et al. (2018) Percutaneous nephrostomy vs ureteral stent for hydronephrosis secondary to ureteric calculi: impact on spontaneous stone passage and health-related quality of life-a prospective study. Urolithiasis. [Crossref]

8. Şimşir A, Kızılay F, Semerci B (2018) Comparison of percutaneous nephrostomy and double J stent in symptomatic pregnancy hydronephrosis treatment. Turk J Med Sci 48: 405-411. [Crossref]

9. Pandey S, Sharma D, Sankhwar S, Singh M, Garg G, et al. Are there any predictive risk factors for failure of ureteric stent in patients with obstructive urolithiasis with sepsis? Investig Clin Urol 59: 371-375. [Crossref]

10. Mokhmalji H, Braun PM, Martinez Portillo FJ, Siegsmund M, Alken P, et al. (2001) Percutaneous nephrostomy versus ureteral stents for diversion of hydronephrosis caused by stones: a prospective, randomized clinical trial. J Urol 165: 1088-1092. [Crossref]

11. Goldsmith ZG, Oredein-McCoy O, Gerber L, Banez LL, Sopko DR, et al. (2013) Emergent ureteric stent vs percutaneous nephrostomy for obstructive urolithiasis with sepsis: patterns of use and outcomes from a 15-year experience. BJU Int 112: E122-E128. [Crossref]
12. Leibovici D, Cooper A, Lindner A, Ostrowsky R, Kleinmann J, et al. (2005) Ureteral stents: morbidity and impact on quality of life. Isr Med Assoc J 7: 491494. [Crossref]

13. Wein AJ, Kavoussi LR, Novick AC, Partin AW, Peters CA (2016) Campbell-Walsh Urology, 11th edn. Elsevier Health Sciences, Philadelphia.

14. Ramsey S, Robertson A, Ablett MJ, Meddings RN, Hollins GW, et al. (2010) Evidencebased drainage of infected hydronephrosis secondary to ureteric calculi. J Endourol 24: 185-189. [Crossref]

15. Joshi HB, Stainthorpe A, MacDonagh RP, Keeley FX Jr, Timoney AG, et al. (2003) Indwelling ureteral stents: evaluation of symptoms, quality of life and utility. $J$ Urol 169: 1065-1069 (discussion 69). [Crossref]

16. Ringel A, Richter S, Shalev M, Nissenkorn I (2000) Late complications of ureteral stents. Eur Urol 38: 41-44. [Crossref]

17. Zheng W, Denstedt JD (2000) Intracorporeal lithotripsy: update on technology. Urol Clin North Am 27: 301-313. [Crossref]

18. Peer A, Strauss S, Witz E, Manor H, Eidelman A (1992) Use of percutaneous nephrostomy in hydronephrosis of pregnancy. Eur J Radiol 15: 220-223. [Crossref]

Copyright: $@ 2019$ Selvi I. This is an open-access article distributed under the terms of the Creative Commons Attribution License, which permits unrestricted use, distribution, and reproduction in any medium, provided the original author and source are credited. 